\title{
Uniaxial Elongational Viscosity of PC/ A Small Amount of PTFE Blend
}

\author{
Takashi KuROSE ${ }^{1)}$, Tatsuhiro TAKAHASHI ${ }^{2 *}$, Masataka SUGIMOTO ${ }^{2)}$, \\ Takashi TANIGUCHI ${ }^{2)}$, and Kiyohito KOYAMA ${ }^{2)}$ \\ 1) Venture Business Laboratory, Yamagata University, Yonezawa 992-8510, Japan \\ ${ }^{2}$ Department of Polymer Science and Engineering, Yamagata University, Yonezawa 992-8510, Japan \\ (Received : February 14, 2005)
}

\begin{abstract}
The uniaxial elongational viscosity of blends, consisting of polycarbonate (PC) and a small amount of polytetrafluoroethylene (PTFE), have been studied. Uniaxial elongational viscosity of blends showed stronger strain-hardening property than that of PC. The structural observations at the fractured cross-section with SEM showed that PTFE fibrils less than $100 \mathrm{~nm}$ in diameter were produced by kneading in molten PC, which were dispersed uniformly in PC matrix. To get deeper insight into the mechanism of the strong strain-hardening, the recoverable strain of the blend samples was investigated, and it was found a large strain recovery occurred after uniaxial elongational deformation. The comparison of the phase morphology before and after strain recovery was performed by observing with SEM. It was confirmed that the diameter of PTFE fibrils increased after strain recovery. WAXD pattern showed that the crystallites of PTFE in PTFE fibrils orientated along the elongational direction by the uniaxial elongational deformation. DSC measurement revealed that $60 \%$ amorphous phase existed in fibrillated PTFE. It was supposed that PTFE fibrils deformed, resulting in the generation of a restoring force, during elongational deformation. These results suggested that the strain-hardening property should be attributed to the generation of the restoring force by stretching of PTFE fibrils.

Key Words: Uniaxial elongational viscosity / Strain-hardening / Poly(tetrafluoroethylene) / PTFE fibril / Nano-scale fibers.
\end{abstract}

\section{INTRODUCTION}

It has been accepted that the elongatinal rheology acts as an excellent indicator for processability. The elongational viscosity gradually increases with time in a small strain region and goes abruptly above a linear viscoelastic envelope, which is called a strain-hardening property. ${ }^{1-3)}$ The strain-hardening property is essential for improving melt processability in blow molding, foaming process, and melt spinning. ${ }^{4-5)}$

Polymer blend and composite technology are effective methods to control the elongational rheology. It is known that the strain-hardening property is enhanced by the existence of long relaxation time components. ${ }^{6-9)}$ This idea has been supported by many melt rheological experiments using homopolymers and miscible polymer blends. Takahashi et al. have reported that the addition of $1.5 \mathrm{wt} \%$ of ultra high molecular weight (UHMW) polymer to a matrix polymer induced a strong strain-hardening property in the homogeneous and miscible polymer blend systems. $\left.{ }^{6}\right)$

On the other hand, it has been observed that the strain-

* To whom correspondence should be addressed

Tel: 81-238-26-3048 Fax: 81-238-26-3047

E-mail: effort@yz.yamagata-u.ac.jp hardening property of polymer composites became smaller than that of matrix polymers. Takahashi et al. investigated uniaxial elongational flow behavior of acrylonitrile-butabienstyrene (ABS) polymer containing hard butadiene particles. The addition of the $20 \mathrm{wt} \%$ butadiene particle made the strainhardening property weaker. ${ }^{10)}$ Moreover, they have also investigated the effect of an addition of various inorganic fillers, such as glass beads and glass fibers, on the strainhardening property of low-density polyethylene (LDPE). The additions of the fillers have never enhanced the strainhardening property of LDPE.11)

We have reported that the unique elongational viscosity property of FEP (tetrafluoroetylene/hexafluoropropylene copolymer) and a small amount of PTFE blend. ${ }^{12)}$ The addition of a small amount of PTFE in solid state to a matrix polymer melt induced stronger strain-hardening, compared with a matrix polymer. DSC measurement and SEM observation showed that PTFE became fibril in a matrix polymer. The structural observations of PTFE fibril had difficulty, because PTFE and FEP have a similar refractive index, and the etching of each materials of blend for structural observation with SEM is not possible due to their chemical resistance. Therefore, the 
mechanism of increase for strain-hardening by the addition of PTFE has not been clarified. Understanding the mechanism is very interesting from both academic and industrial points of view.

The objective of the present study is clarifying the mechanism of the enhancement for the strain-hardening by the addition of PTFE. PTFE powder was added to a polycarbonate (PC). The reason in use of PC was that PC allowed us to perform in similar experimental situations to FEP/PTFE blend system such as mixing temperature and melt viscosity. Moreover, PC enabled us to perform the chemical etching.

First of all, the characterizations of PC/PTFE blend such as thermal property and morphology were investigated to clarify whether PTFE were fibrillated and dispersed even in the PC matrix polymer or not. Secondly, rheological measurements were conducted. Thirdly, experiments to clarify the effect of the addition of PTFE on elongational viscosity were carried out.

\section{EXPERIMENTAL}

\subsection{Materials}

PTFE (Teflon ${ }^{\circledR}$ PTFE 6-J) was kindly supplied by DupontMitsui Fluorochemicals Co., Ltd. The average diameter of PTFE powder was $470 \mu \mathrm{m}$, which was prepared through emulsion polymerization. PC (Panlite ${ }^{\circledR}$ K-1300, Teijin Chemicals Co., Ltd., MFR=2.5 g/10 min) was used as a matrix polymer.

\subsection{Sample Preparations}

PC and PTFE were mixed in various proportions (PC/PTFE: 100/0, 99.5/0.5, 99/1, and 98/2 (volume ratio)). Firstly, PC was molten in a batch type twin-screw kneader (Labo Plastomill, Toyoseiki Co., Ltd.) at $280{ }^{\circ} \mathrm{C}$ for 3 minutes. Then, PTFE powder was added by inches. Finally, the mixture was kneaded intimately (72 rpm) for 10 minutes. The kneaded sample was crushed into powders to go through the mesh with holes of $2 \mathrm{~mm}$ in a diameter. Unless otherwise specified, the crushed samples were used in this study.

The sample to perform DSC and rheological measurement was molded as follows: Firstly, the crushed sample was molten in the mold at $240{ }^{\circ} \mathrm{C}$ for 10 minutes, and then pressed under $10 \mathrm{MPa}$ for 5 minutes and cooled to room temperature. Figure 1 illustrates the flow chart of the sample preparations. It is noted that when samples were molded at $240{ }^{\circ} \mathrm{C}$ without crushing, samples deformed by themselves heterogenously during melting time before rheological measurements, so that it was impossible to conduct uniaxial elongational measurements without the crush of blends.

\subsection{Thermal Properties}

Thermal analysis (non-isothermal) of neat PC, neat PTFE, and PC/PTFE 98/2 were performed with a differential scanning calorimeter (DSC 2920, TA instruments Co., Ltd.). Measurements were performed with $10 \pm 1.0 \mathrm{mg}$ samples in nitrogen atmosphere from $100^{\circ} \mathrm{C}$ to $360^{\circ} \mathrm{C}$ at a heating rate of $10{ }^{\circ} \mathrm{C} / \mathrm{min}$ and kept at $360{ }^{\circ} \mathrm{C}$ for $5 \mathrm{~min}$, cooled to $100^{\circ} \mathrm{C}$ at a cooling rate of $5{ }^{\circ} \mathrm{C} / \mathrm{min}$, and then reheated to $360{ }^{\circ} \mathrm{C}$ at $10^{\circ} \mathrm{C} / \mathrm{min}$. The reproducible data of DSC measurements were obtained.

\subsection{Scanning Electron Microscopy (SEM) Observations}

SEM observations were performed with a SEM (JSM-5310, JEOL Co., Ltd.). The fracture cross-section and the surface were observed. PC on the surface of the samples was removed by alkali etching before SEM observation. The fracture of sample was performed in use of an edged tool after immersing a sample for 15 minutes in liquid nitrogen. The samples were coated with gold in the thickness about $200 \AA$ using an ion spattering apparatus to eliminate charging in electron beam. The pictures of microstructure were taken with a Polaroid camera. Field emission SEM (FE-SEM) (JSM-6330F, JEOL Co., Ltd.) was also utilized to observe the fracture crosssection in high magnification. The pictures were taken into the attached personal computer.

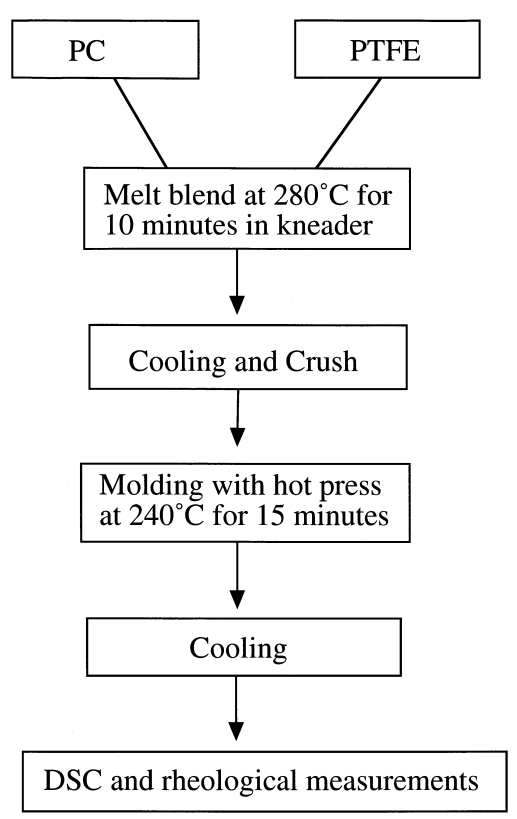

Fig. 1. Flow chart of sample preparation to perform DSC and rheological measurements. 


\subsection{Wide Angle X-ray Diffraction (WAXD) Measurements}

Wide-angle X-ray diffraction (WAXD) photographs were recorded on an imaging plate at $24^{\circ} \mathrm{C}\left(\mathrm{R}-\mathrm{AXIS} \mathrm{IV}{ }^{++}\right.$, Rigaku Co., Ltd.). X-ray was generated with nickel-filtered $\mathrm{CuK} \alpha$ on $40 \mathrm{kV}$ and $20 \mathrm{~mA}$. The length between sample and imaging plate was $150 \mathrm{~mm}$. Diameter of collimators was $200 \mu \mathrm{m}$. The orientation function of a axis in PTFE crystallite $f_{\alpha}$ was estimated by the X-ray diffraction method using following equations

$$
\begin{aligned}
& f_{a}=\frac{1}{2}\left(3<\cos ^{2} \theta>-1\right) \\
& <\cos ^{2} \theta>=\frac{\int_{0}^{\frac{\pi}{2}} I(\phi) \cos ^{2} \phi \sin \phi d \phi}{\int_{0}^{\frac{\pi}{2}} I(\phi) \sin \phi d \phi}
\end{aligned}
$$

where $\theta$ is angle between elongational direction and chain axis in PTFE crystallite, and $I(\phi)$ is the azimuthal intensity distribution of the hexagonal (100) plane reflection of PTFE crystallite. $<\cos ^{2} \theta>$ in Eq. (2) was calculated by using the attached soft ware. Since it has been known that the crystal structure of PTFE at $24^{\circ} \mathrm{C}$ shows hexagonal, the orientation function of chain axis in PTFE crystallite $f_{c}$ is determined by following equation. ${ }^{13,14)}$

$$
f_{c}=-2 f_{a}
$$

\subsection{Melt Rheological Measurements}

Dynamic shear measurements over the frequency range from 0.1 to $100(\mathrm{rad} / \mathrm{s})$ were carried out by means of a $25 \mathrm{~mm}$ parallel-prate rheometar (ARES, TA Instruments Co., Ltd.) at $280^{\circ} \mathrm{C}$ under air atmosphere. The magnitude of shear strain was determined within a linear viscoelastic region. Step-shear stress relaxation experiments were performed with applying different step-shear strains, $0.1,0.3,0.5,0.7,1.0,2.0$, and 3.0 at $240{ }^{\circ} \mathrm{C}$ under nitrogen atmosphere. Generally, stress relaxation modulus of polymer $G(t, \gamma)$, where $t$ is a time and $\gamma$ is a shear strain, can be expressed below

$$
G(t, \gamma)=G(t) h(\gamma) \quad \text { at long } t
$$

where $G(t)$ is a linear relaxation modulus and $h(\gamma)$ is a damping function. ${ }^{15)}$ The geometry was parallel plates with a diameter of $25 \mathrm{~mm}$ (ARES, TA Instruments Co., Ltd.). The reproducible data of relaxational modulus were checked by applying the both clockwise and counter clockwise step-shear strains.
Uniaxial elongational measurements under constant strain rates $\left(0.05-0.5\left(\mathrm{~s}^{-1}\right)\right)$ were performed using a uniaxial elongational rheometer (RME, TA Instruments Co., Ltd.) at $200{ }^{\circ} \mathrm{C}$ and $220{ }^{\circ} \mathrm{C}$ under nitrogen atmosphere. Actual temperature was within the deviation of $0.5^{\circ} \mathrm{C}$ from each setting temperature. It was confirmed that reproducible data within $10 \%$ were obtained, and the deformation of samples was completely uniform within 2 in Hencky strain. Actual strain rate was estimated by checking the width variation of samples during elongational measurements using a CCD camera. The sample shapes for dynamic shear and step-shear strain measurements were $25 \mathrm{~mm}$ diameter disk in the thickness of $1 \mathrm{~mm}$, and that for uniaxial elongational measurements was square bar $(1.5 \times 7.0 \times 55 \mathrm{~mm})$.

\section{RESULTS AND DISCUSSION}

\subsection{Thermal Properties}

Figure 2 shows DSC curves of neat PC, neat PTFE, and PC/ PTFE 98/2 blend at second heating runs. Two separated heat flow peaks were observed in blend sample. It was found that the lower melting peak corresponded to the glass transition temperature of neat $\mathrm{PC}$ and the higher one corresponded to the melting temperature of neat PTFE, respectively. Figure 3 gives the DSC cooling curves of these samples. The point of inflection was seen around $160{ }^{\circ} \mathrm{C}$ in PC/PTFE blend sample, which corresponded to glass transition temperature of neat PC. The heat flow peak around $320^{\circ} \mathrm{C}$ also corresponded to the crystallization temperature of neat PTFE. The results of DSC heating and cooling runs indicated that PC and PTFE were mixed in immiscible state.

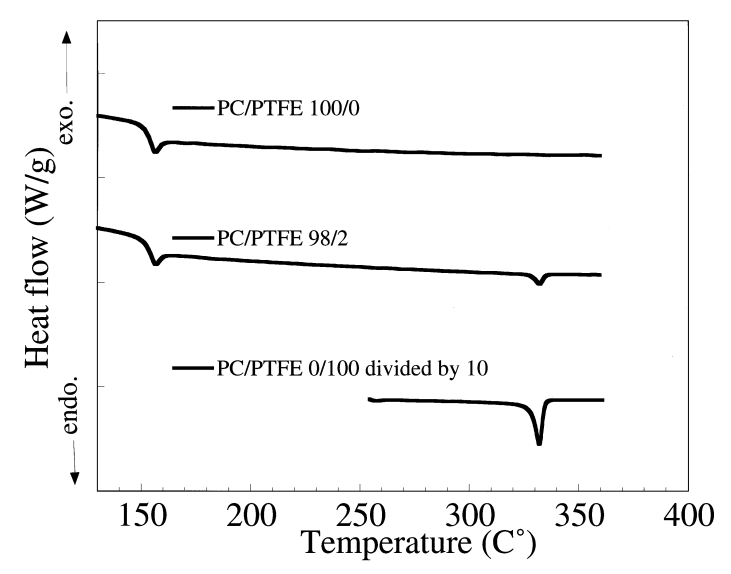

Fig. 2. DSC melting curves (2nd heating runs) under heating up rate of $10{ }^{\circ} \mathrm{C} / \mathrm{min}$ for PC/PTFE $100 / 0,98 / 2$, and $0 / 100$. The value of PC/ PTFE 0/100 was divided by 10 . 


\subsection{Structural Observation by Scanning Electron Microscopy (SEM)}

To clear morphology of blend sample, SEM observations at the fractured cross-section of neat PC and PC/PTFE 98/2 blend were performed, which are shown in Figs. 4 (a)-(c). The brittle fracture of neat PC was observed in Fig. 4 (a). On the other hand, PC/PTFE blend had a quite different fracture crosssection as seen in Fig. 4 (b). Many fibrils less than $1 \mu \mathrm{m}$ in diameter were obviously stuck out of the fracture surface, which was supposed to be PTFE fibrils. We have reported that the results for the morphological observation of FEP/PTFE blend with an optical microscopy and SEM. ${ }^{12)}$ The results showed that PTFE was obviously fibrillated by kneading with molten FEP. As shown in Fig. 4 (c), the observation by FESEM in high magnification revealed that there were fine fibrils around $100 \mathrm{~nm}$ in a diameter. From SEM observations, it was found that PTFE was also fibrillated in PC matrix in the same as to the blend between FEP and PTFE.

\subsection{Dynamic Shear Measurements}

The oscillatory shear experiments of PC/PTFE 98/2 blend were performed at $280^{\circ} \mathrm{C}$. The result was shown together with neat $\mathrm{PC}$ in Fig. 5 . Figure 5 showed that the height of $G$ ' toward lower frequency region became larger by the addition of PTFE, but $G$ " was similar between samples. The results suggested that long relaxation time components existed in PC/ PTFE blend. The tendency has been reported in fine particles and fiber dispersed polymer systems. ${ }^{16,17)}$ DSC experiments and SEM observations supported the fact that PTFE were dispersed as a phase-separated fibrous structure, therefore, it is supposed that fibrils or network structure formed by fibrils would generate the elastic response in lower frequency region.

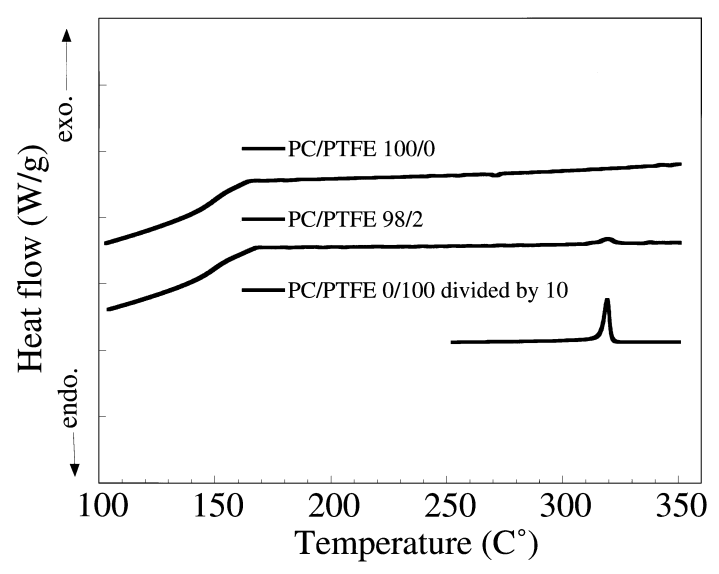

Fig. 3. DSC crystallization behavior under cooling rate of $5{ }^{\circ} \mathrm{C} / \mathrm{min}$ for PC/PTFE $100 / 0,98 / 2$, and 0/100. The value of PC/PTFE $0 / 100$ was divided by 10 .

\subsection{Step-Shear Relaxation Measurements}

Figures 6 (a) and (b) show the results of step-shear stress relaxation measurement for neat PC and PC/PTFE 98/2 blend at $240{ }^{\circ} \mathrm{C}$, respectively. It was observed that the relaxation of $G(t, \gamma)$ for PC/PTFE blend was slower than that for neat PC. It seems that there are two mechanisms of relaxation in Fig. 6 (b), which are short time relaxation mechanism less than $1(\mathrm{~s})$ and long time relaxation mechanism more than $1(\mathrm{~s})$. In filler dispersed polymer systems, two mechanisms of relaxation (fast and slow relaxation processes) have been often seen. ${ }^{17,18)}$ The former reflects the relaxation of matrix polymer chain from orientation, and the latter is attributed to the relaxation for motions of fillers and their agglomerate structure.

In Fig. $6(\mathrm{a})$, the $G(t, \gamma)$ curves less than $100 \%$ of strain $(\gamma<100 \%)$ in neat PC were very close to each other, which were considered as a linear relaxation modulus $G(t)$. However,
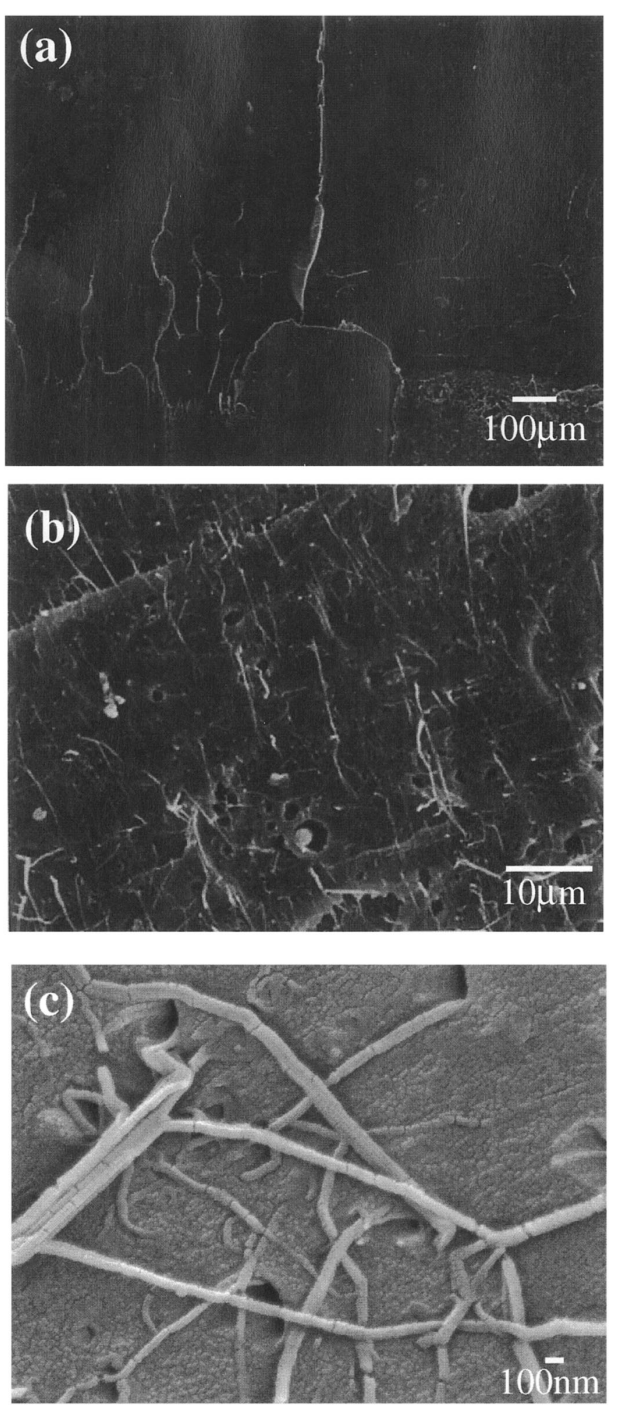

Fig. 4. SEM photographs of fracture cross-section for (a) PC/PTFE 100/ 0, (b) PC/PTFE 98/2, and (c) PC/PTFE 98/2. (c) was observed with FE-SEM. 
$G(t, \gamma)$ decreased over $100 \%$ of strain $(\gamma>100 \%)$, which is called damping property. It has been known that the damping of polymer melt is commonly attributed to the chain shrinkage occurring faster than the orientational relaxation after step shear strain. ${ }^{15,19)}$ The time-strain separability was valid in neat PC, but not valid in PC/PTFE blend. We evaluated the damping function below

$$
h(\gamma)=[G(t, \gamma) / G(t)]_{t=0.2,1.0 s}
$$

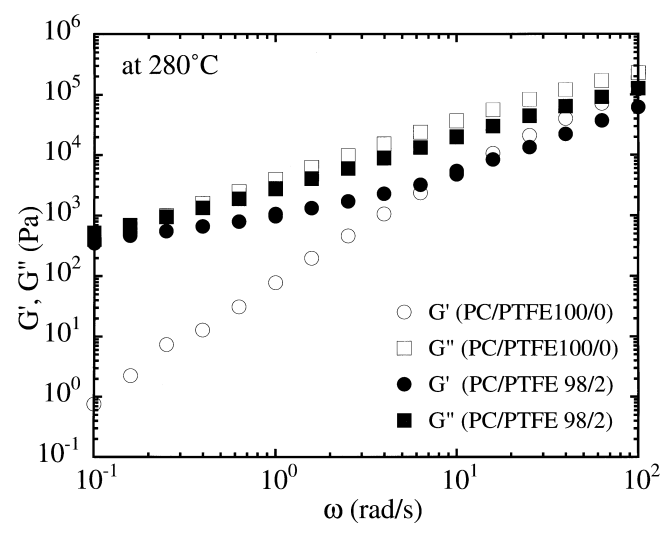

Fig. 5. Storage modulus $G^{\prime}$ and loss modulus $G^{\prime \prime}$ as a function of angular frequency for PC/PTFE $100 / 0$ and $98 / 2$ at $280^{\circ} \mathrm{C}$.
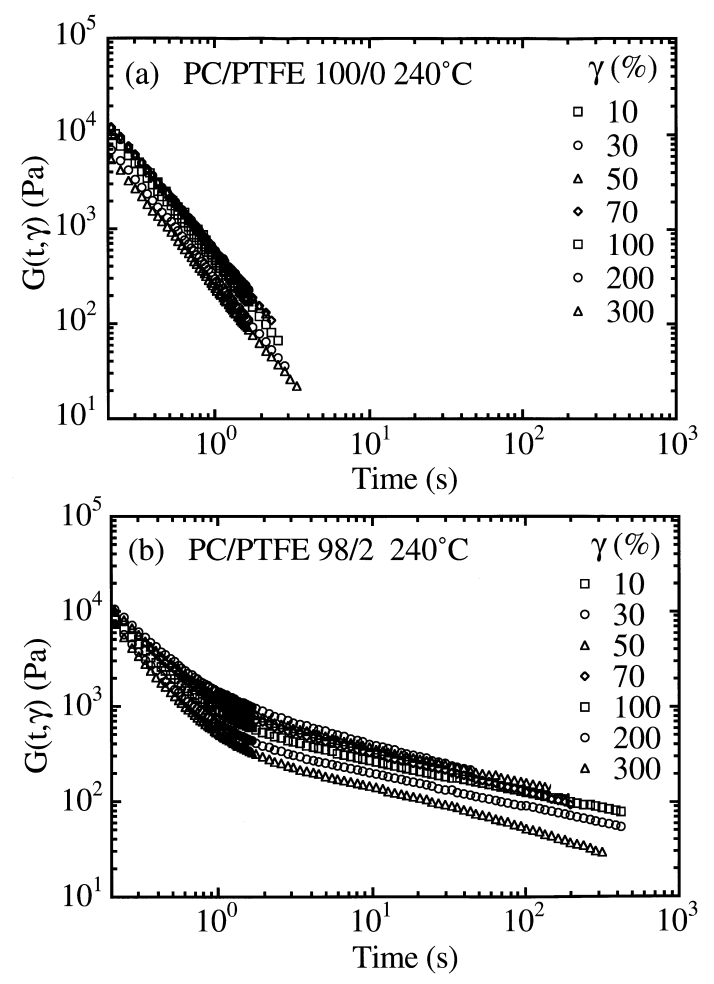

Fig. 6. Step-shear relaxation modulus $G(t, \gamma)$ of (a) PC/PTFE $100 / 0$ and (b) $98 / 2$ at $240{ }^{\circ} \mathrm{C}$.
Reference times utilized in Eq. (5) were 1.0 (s) and 0.2 (s).

Figure 7 illustrates the damping function $h(\gamma)$ of neat PC $(t=1.0(\mathrm{~s}))$ and PC/PTFE blend $(t=0.2,1.0(\mathrm{~s}))$. Damping function of Doi-Edwards prediction was also shown in Fig. 7 as a reference. ${ }^{15)}$ It was found that the magnitude of damping for PC/PTFE blend $(t=0.2(\mathrm{~s}))$ was weaker than that of PC/ PTFE blend $(t=1.0(\mathrm{~s}))$. It is importantly noted that the damping of PC/PTFE blend $(t=0.2(\mathrm{~s}))$ was weaker than that of neat $\mathrm{PC}$ in large strain region. Generally, an addition of fillers to polymer matrix makes the magnitude of damping stronger. Aoki et al. have reported the nonlinear damping behavior of the ABS polymer. Their data showed that the magnitude of damping for ABS became stronger than that of pure SAN matrix polymer. ${ }^{17)}$ Since rubber particles were much stiffer than SAN chains, the rubber particles effectively worked as solid fillers. The strong damping by the addition of nondeformed filler was explained by the idea that the local strain in the matrix is larger than strain applied externally. ${ }^{17,20)}$

The weak damping of PC/PTFE blend $(t=0.2(\mathrm{~s}))$ in Fig. 7 indicates a lager generation of shear stress than that of neat PC in large strain region. It is supposed that the difference from the typical property of filler dispersed polymer system depends on whether the fillers deform during shear deformation or not. If PTFE fibrils deform together with shear deformation, the shear stress of blend sample may increase compared with that of neat PC, which should lead to the weak damping property of PC/PTFE blend $(t=0.2(\mathrm{~s}))$.

\subsection{Uniaxial Elongational Measurements}

Figures 8 (a) and (b) show the results for uniaxial elongational viscosity measurements of neat PC and 98/2 blends at $200{ }^{\circ} \mathrm{C}$ and $220^{\circ} \mathrm{C}$, respectively. Though neat PC hardly showed a strain-hardening property, the blends clearly showed the strain-hardening property. It should be noticed that

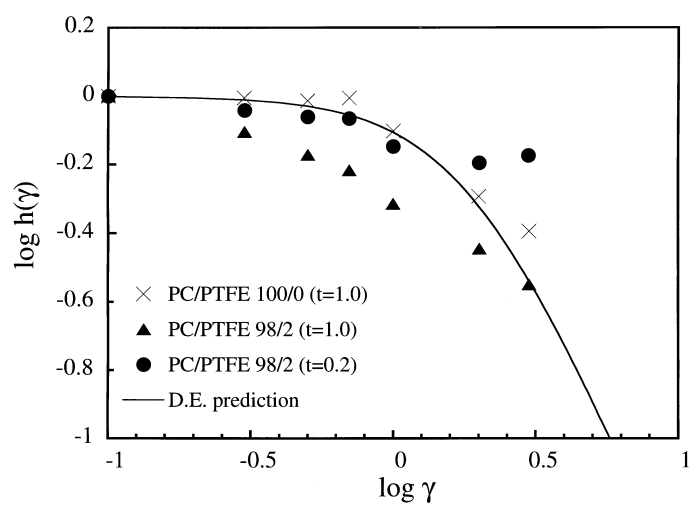

Fig. 7. Damping function $h(\gamma)$ of PC/PTFE $100 / 0(t=1.0), 98 / 2(t=0.2$ and $1.0)$, and Doi-Edwards prediction ${ }^{15)}$. 
the degree of strain-hardening for $220^{\circ} \mathrm{C}$ is larger then that for $200{ }^{\circ} \mathrm{C}$. The reason is explained in the latter section (3.11 The Effect of an addition of PTFE on the elongational stress). Generally, it has been observed that the strain-hardening property of filler dispersed polymer system including hard particles or fibers became smaller compared with that of matrix polymer. $^{10,11)}$

In spite of filler dispersed polymer system, PC/PTFE blend showed stronger strain-hardening property than that of PC. Though we have reported the similar strain-hardening property in FEP/PTFE blend system ${ }^{12}$, the mechanism about the generation of the strain-hardening by the addition of PTFE have not been clarified. Because of the difficulty of the structural observation of PTFE fibrils in FEP/PTFE blends. The experiments to clarify the mechanism were performed and discussed in use of the PC/PTFE blend sample from the next section.

\subsection{Strain Recovery Measurements}

Strain recovery measurements were performed with monitoring the variation of the sample length during annealing of elongated samples. Neat PC and PC/PTFE 98/2 blend sample were elongated with an elongational rheometer (Melten rheometer, TOYOSEIKI Co., Ltd.) in silicone oil bath at $200{ }^{\circ} \mathrm{C}$. After samples were elongated up to 1 or 2 in Hencky strain at strain rate of $0.1\left(\mathrm{~s}^{-1}\right)$, samples were taken quickly from cramps and put into a water bath. The initial length of quenched sample was $9 \mathrm{~cm}$. The quenched sample was put into a silicone oil bath at $200{ }^{\circ} \mathrm{C}$ again. The variation of the sample length in the silicone oil bath was monitored by CCD camera.

Figure 9 (a) shows sample shapes of PC/PTFE and neat PC after annealed at $200{ }^{\circ} \mathrm{C}$ for 4 hours. It was interestingly observed that though neat PC hardly showed strain recovery
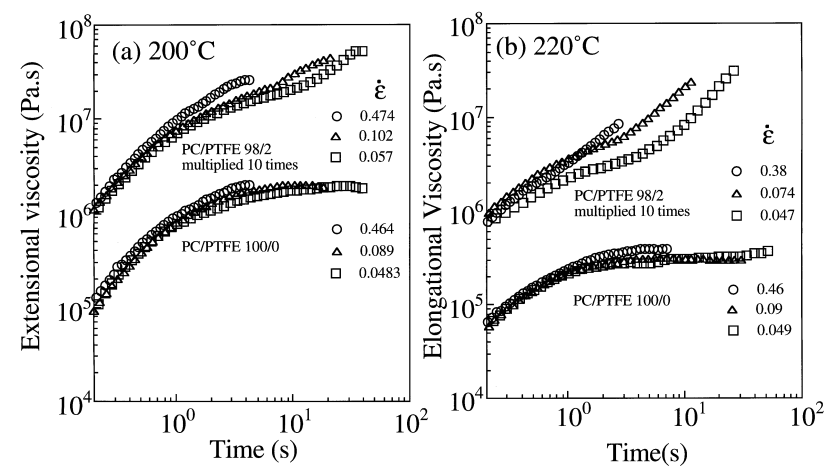

Fig. 8. Uniaxial elongational viscosity of PC/PTFE 100/0 and 98/2 under constant strain rates at (a) $200{ }^{\circ} \mathrm{C}$ and (b) $220{ }^{\circ} \mathrm{C}$. The values of PC/PTFE 98/2 were multiplied 10 times. property, PC/PTFE blend showed a large strain recovery property. Figure 9 (b) shows the variation of the length for blend sample as a function of time. It was shown that the samples rapidly recovered within 1 hour, then the samples recovered slowly after 1 hour. Dotted lines express the length when samples could completely recover (initial length $9 \mathrm{~cm}$ was divided by extensional times). Since it is clear that the existence of PTFE fibrils caused a strain recovery property, the strain recovery property would be attributed to the motion of PTFE fibrils in PC matrix. It is supposed that the large strain recovery would be related to the strain-hardening property.

\subsection{Orientation of PTFE Crystallites in PTFE Fibers}

WAXD measurement and SEM observation of neat PTFE sample were performed to clarify the orientation of PTFE crystallites in PTFE fibers. PC/PTFE 98/2 blend sample elongated up to 2 in Hencky strain was immersed in $30 \mathrm{wt} \%$ sodium hydroxide solution at $110{ }^{\circ} \mathrm{C}$ for 20 hours in order to remove the $\mathrm{PC}$ matrix polymer. The etched sample was washed in purified water and dried at room temperature. Then, neat PTFE sample consisted of PTFE fibrils was prepared.

SEM observation of neat PTFE sample was conducted to observe the orientation of PTFE fibers, which are shown in Figs. 10 (a) and (b). It was found that PTFE fibrils less than $1 \mu \mathrm{m}$ in diameter were highly orientated along the elongational
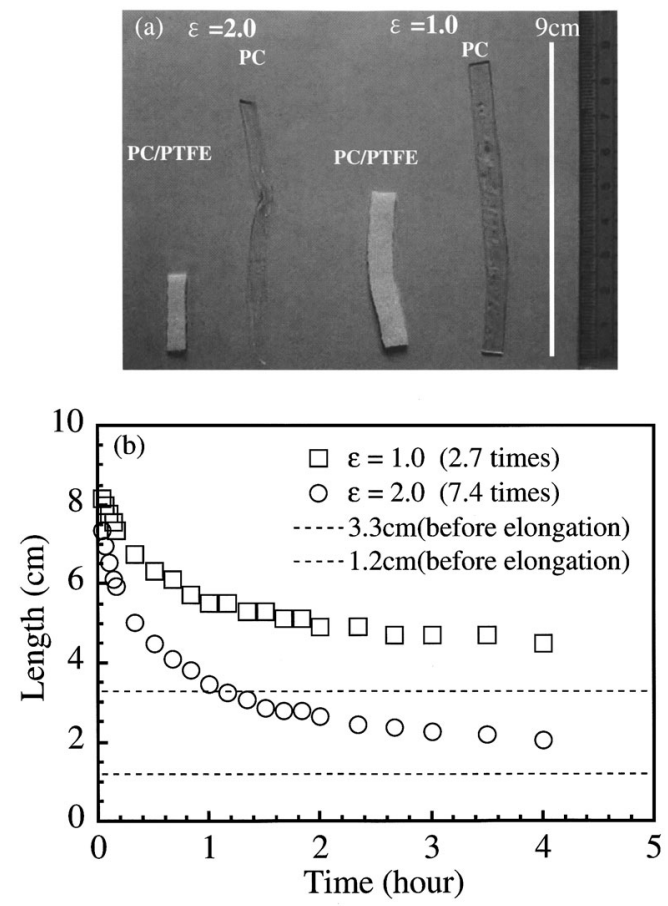

Fig. 9. (a) Photographs of PC/PTFE 100/0 and PC/PTFE 98/2 samples after annealing. (b) The variations of sample length during annealing at $200^{\circ} \mathrm{C}$. 
direction. Figure 10 (c) shows the WAXD pattern of above sample. Though the SEM photographs showed that PTFE fibers were highly orientated along the elongational direction, the WAXD patterns exhibited almost uniform ring(orientation function $f_{c}$ was 0.25 ), indicating that PTFE crystallites in PTFE fibers were randomly distributed.

\subsection{SEM Observations of Elongated Sample}

SEM observations of PC/PTFE 99.5/0.5 blend sample after elongation and annealing were performed to investigate the configurational variation of PTFE fibrils. The elongation of sample was performed using elongatoinal rheometer in the same way as mentioned above (3.6 strain recovery measurement). To observe the PTFE fibrils clearly, the PC on the only surface of sample was etched by immersing in $30 \mathrm{wt} \%$ sodium hydroxide solution at $110^{\circ} \mathrm{C}$ for 2 hours.

Figures 11 (a)-(c) show SEM photographs of the sample before elongation (Fig. 11 (a)), after elongation (Fig. 11 (b)), and after annealing (Fig. 11 (c)). PTFE fibrils were clearly observed by alkali etching. As shown in Fig. 11 (a), it was observed that the direction of PTFE fibers in before elongation samples was isotropic. Figure 11 (b) shows SEM photograph of elongated sample up to 2 in Hencky strain. It was found that
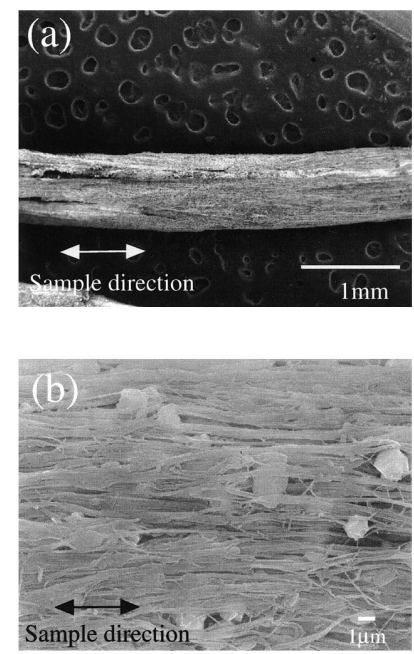

(c)

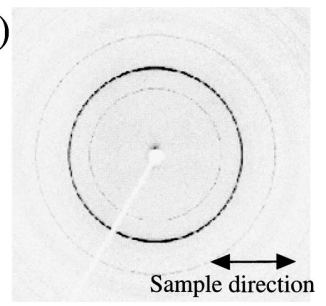

Fig. 10. (a) Overview of neat PTFE sample with SEM. (b) SEM photograph of neat PTFE sample in high magnification. (c) WAXD pattern of neat PTFE sample.
PTFE fibers were orientated along the elongational direction. Figure 11 (c) shows SEM photograph of annealed sample for 4 hours at $200{ }^{\circ} \mathrm{C}$, it was clearly observed that the orientations of fibers became isotropic and the diameter of fibrils increased by annealing.

\subsection{WAXD (Wide-Angle X-ray Diffraction) Measurements}

WAXD measurements of neat PC and PC/PTFE 98/2 before elongation, after elongation, and after anneal were performed at $24^{\circ} \mathrm{C}$, which are shown in Figs. 11 (d)-(g). Figure 11 (d) shows the WAXD pattern of PC elongated up to 2 in Hencky strain. The WAXD pattern exhibited the only halo attributed to amorphous PC molecular chain. Figure 11 (e) shows the WAXD pattern of PC/PTFE blend before elongation. The WAXD pattern showed an uniform ring, which indicated that
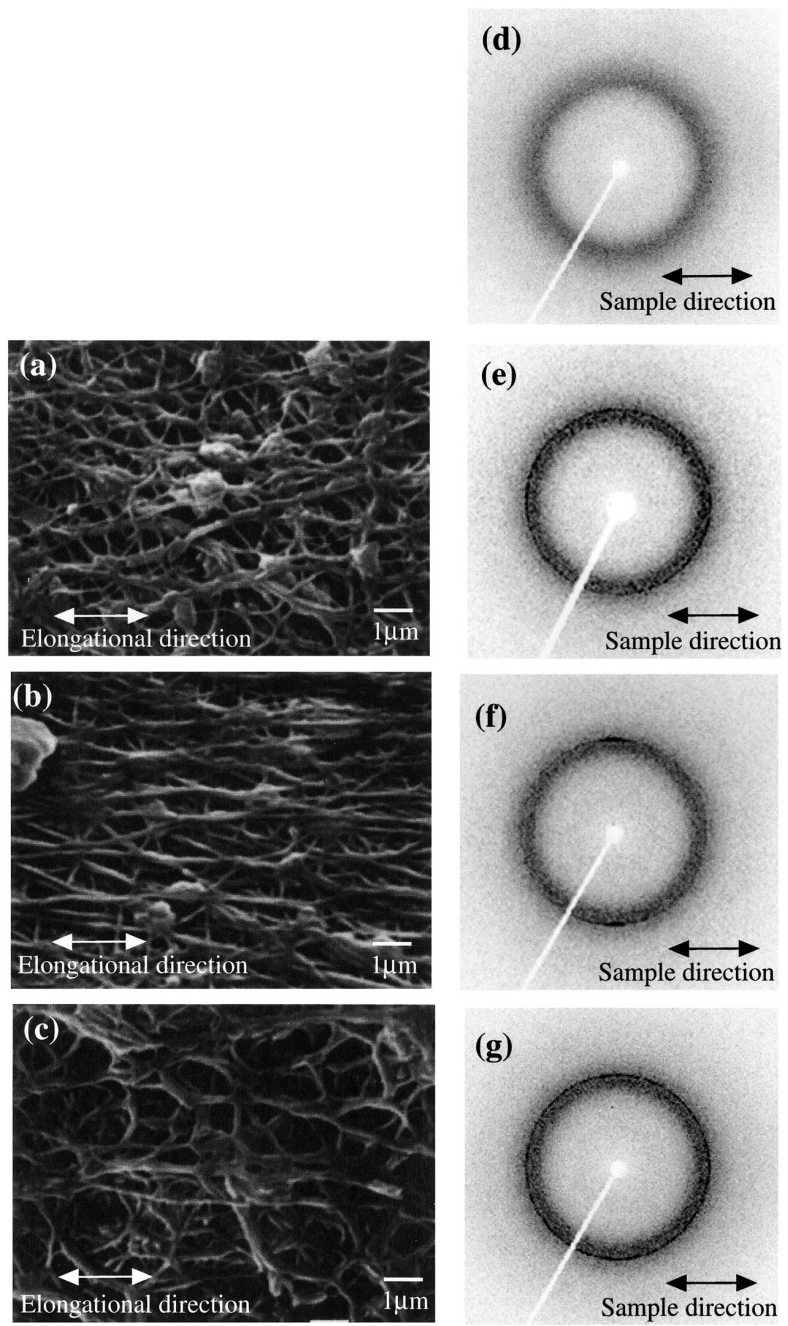

Fig. 11. SEM photographs of PC/PTFE 99.5/0.5 blend sample of (a) before elongation, (b) after elongation up to 2 in Hencky strain, and (c) after annealing for 4 hours. WAXD patterns of (d) neat PC elongated up to 2 in Hencky strain, (e) before elongation of PC/ PTFE 98/2 blend, (f) after elongation of PC/PTFE 98/2 blend up to 2 in Hencky strain, and (g) after annealing of PC/PTFE 98/2 blend. 
the PTFE crystallites were randomly orientated in the sample. Figure 11 (f) shows the WAXD pattern of PC/PTFE blend elongated up to 2 in Hencky strain. Figure 11 (f) exhibited a narrow intensity distribution along the azimuthal direction on the halo of amorphous PC (orientation function $f_{c}$ was 0.48 ), which suggested that the PTFE crystallites were significantly orientated to the elongational direction. Based on the fact that the PTFE crystallites in PTFE fibrils hardly orientated even if PTFE fibers highly orientated as shown in Fig. 10 (c), it would be safe to state that the orientation of PTFE crystallites was attributed to stretching of PTFE fibrils during elongation of sample. It is supposed that stretched PTFE fibrils in the PC matrix would be relaxed by removing the PC matrix, and isotropic WAXD pattern was observed in Fig. 10 (C) in spite of highly orientation of fibrils.

Figure $11(\mathrm{~g})$ shows the WAXD pattern of annealed sample. The annealing of elongated sample was performed in a silicone oil bath at $200{ }^{\circ} \mathrm{C}$ for 4 hours. The WAXD pattern of the annealed sample also exhibited uniform ring (orientation function $f_{c}$ was 0.1 ), indicating that the PTFE crystallites were randomly distributed in the blend sample.

\subsection{DSC Measurements of Elongated Samples}

Generally, it has been recognized that PTFE fibrils do not deform largely, since it has been considered that PTFE fibril is constructed with extended crystal chains ${ }^{21,22)}$, and the crystallinity of virgin PTFE is very high. ${ }^{23)}$ To clarify the percentages of crystal phase in the PTFE fibrils, the crystallinity of PTFE fibrils was measured with DSC. The variations of the PTFE crystallinity of the samples before elongation, after elongation, and after annealing were also investigated with DSC. Figure12 shows the results for DSC

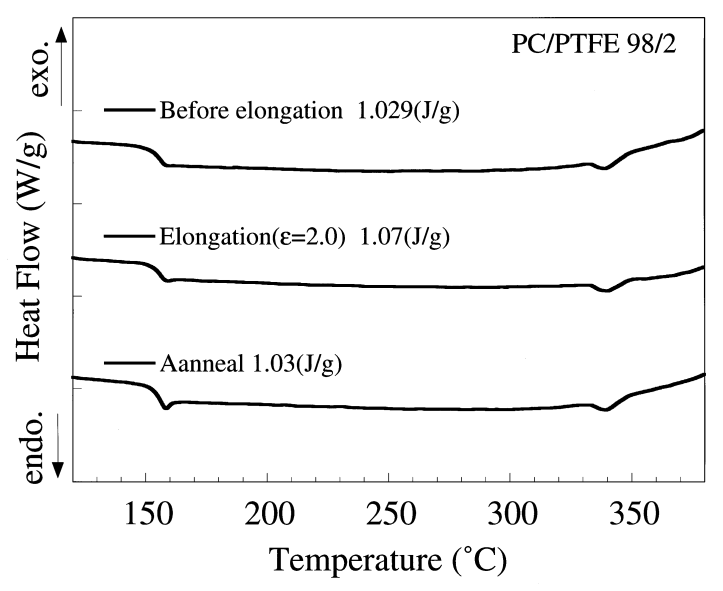

Fig. 12. DSC heating curves under heating up rate of $10{ }^{\circ} \mathrm{C} / \mathrm{min}$ of $\mathrm{PC} /$ PTFE 98/2 blend samples before elongation, after elongation up to 2 of Hencky strain, and after annealing at $200{ }^{\circ} \mathrm{C}$ for 4 hours. measurements of PC/PTFE blend sample before elongation, after elongation, and after annealing. The points of inflection around $160^{\circ} \mathrm{C}$, attributed to glass transition temperature of $\mathrm{PC}$, were seen in all samples. The heat flow peaks around $340{ }^{\circ} \mathrm{C}$ corresponding to melting temperature of PTFE were seen in all the samples. It was found that endothermic values attributed to melt of PTFE crystal were around $1.0(\mathrm{~J} / \mathrm{g})$ in all the samples, which allow us to state that the variations of crystalline structure do not occur accompanied with elongation and annealing. The crystallinity of PTFE fibril was estimated at $40 \%$, based on the fact that the endothermic value of samples of PTFE crystals requires $93(\mathrm{~J} / \mathrm{g})^{24,25)}$, which expressed that PTFE fibrils had amorphous phase of $60 \%$. It was supposed that the large deformation of PTFE fibrils should occur in amorphous phase of the PTFE fibrils.

Based on the results from SEM observations, WAXD measurements, and DSC measurements, the models of PC/ PTFE blend sample drawing the orientation and the deformation of PTFE fibrils are illustrated in Figs. 13 (a) and (b). PTFE fibrils are distributed in isotropic, and the PTFE crystallites in the PTFE fibrils are also randomly distributed in before elongation sample (Fig. 13 (a)). However, PTFE fibrils are orientated along the elongational direction, and the PTFE crystallites in the PTFE fibrils also orientated accompanied with the elongational deformation of sample (Fig. 13 (b)).

\subsection{The Effect of an Addition of PTFE on the Elongational Stress.}

The effect of the addition of PTFE on elongational stress was investigated. The elongational stress of neat $\mathrm{PC}$ measured at $200{ }^{\circ} \mathrm{C}$ and $220^{\circ} \mathrm{C}$ were subtracted from that of PC/PTFE $98 / 2$ blend sample in each strain rate, respectively. The results

(a) Before elongation

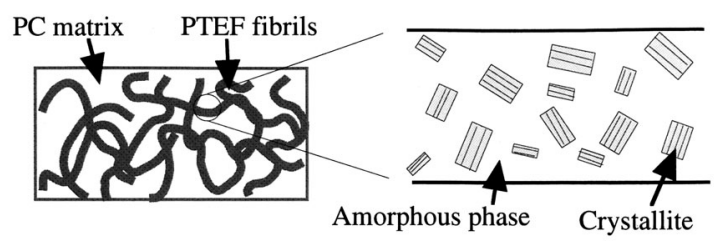

(b) After elongation Amorphous phase Crystallite

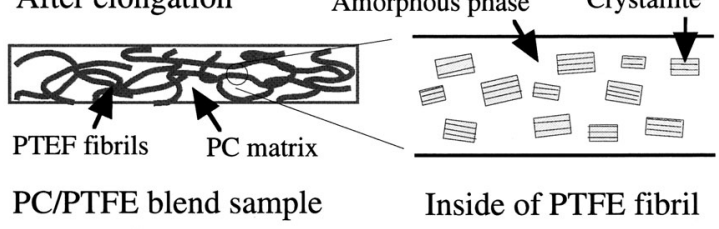

Fig. 13. Schematic models of PTFE fibrils in the blend sample (a) before elongation and (b) after elongation. 
are shown in Fig.14, which should indicate the effect of the addition of PTFE on the extensional stress in PC/PTFE blends. The results showed almost similar behavior, suggesting that the effect of the addition of PTFE on elongational property was not changed by temperature and strain rate.

The extensional stress of neat PTFE sample is also shown in Fig. 14. Neat PTFE sample consisted of PTFE fibrils was prepared by alkali etching as mentioned above ( 3.7 orientation of PTFE crystallites in PTFE fibers). Then, Neat PTFE sample was extended up to 1 in Hencky strain at $200{ }^{\circ} \mathrm{C}$ with extensional apparatus (ARES, TA instrument Co., Ltd.). The extensional stress of the neat PTFE sample was estimated with dividing the tension of the neat PTFE sample by the cross section area same as to PC/PTFE blend sample. The extensional stress of neat PTFE sample and the effect of the addition for PTFE on the extensional stress of PC/PTFE blend were compared. It was found that the both values showed quite similar behavior. Based on the fact that PTFE fibrils should be stretched surely in extensional apparatus, it would be safe to state that PTFE fibrils in blend sample would be stretched accompanied with elongatinal deformation of matrix.

The proposed mechanism could explain the reason why the degree of strain-hardening at $220^{\circ} \mathrm{C}$ is larger than that at $200{ }^{\circ} \mathrm{C}$ in Fig. 8. The height of the linear viscoelastic envelope at $220^{\circ} \mathrm{C}$ becomes quite smaller than that at $200^{\circ} \mathrm{C}$ due to the sensibility of $\mathrm{PC}$ to temperature. On the other hand, nonlinear viscosity is almost dominated by the stress from the stretch of PTFE, which hardly depends on temperature. Therefore, it would be observed that the degree of strain-hardening at $220{ }^{\circ} \mathrm{C}$ is relatively larger then that at $200{ }^{\circ} \mathrm{C}$.

It is found that the linear viscoelastic envelope of the elongational viscosity for blends is highly influenced by the

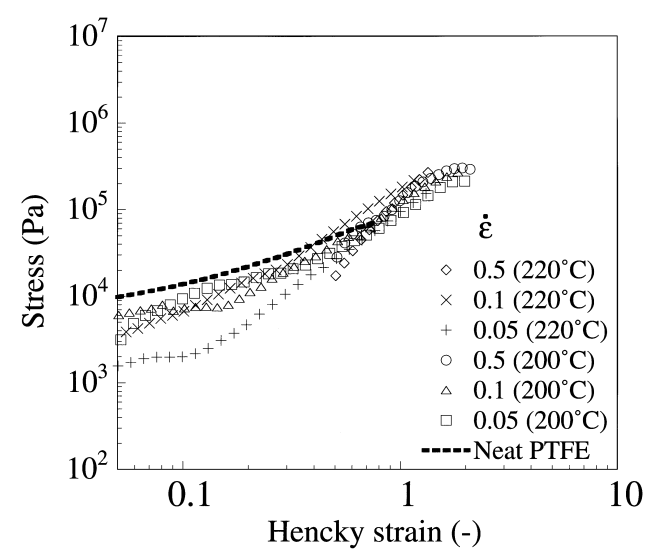

Fig. 14. Elongational stress estimated by subtracting stress( $\mathrm{PC})$ from stress(PC/PTFE) in each strain rate at $200{ }^{\circ} \mathrm{C}$ and $220{ }^{\circ} \mathrm{C}$. Elongational stress of neat PTFE sample. deformation of matrix polymer, and nonlinear viscosity is by the stretch of fibrils. The influence of the stretch for fibrils on rheological property was observed as an elastic effect. There is possibility that the network structures are formed with fibrils in blends, which is speculated from the results that long relaxation time components are observed in rheological measurements under shear deformation (Fig. 5 and Fig. 6). It is supposed that the formation of network structure could make the orientation of fibrils easily, and might influence on elongational viscosity slightly.

\section{CONCLUSION}

The uniaxial elongational viscosity of the blend consisting of polycarbonate $(\mathrm{PC})$ and a small amount of polytetrafluoroethylene (PTFE) has been studied. It was clearly observed that PTFE fibrils less than $100 \mathrm{~nm}$ in a diameter were generated by kneading with molten PC. The uniaxial elongational viscosity of the blend showed stronger strain-hardening property than that of PC.

The experiments to clarify the mechanism of enhanced strain-hardening were performed. It was found that blend sample showed large strain recovery property. SEM observations showed that the diameter of PTFE fibrils increased after the strain recovery. The WAXD patterns showed that the PTFE crystallites in PTFE fibrils orientated along the elongational direction. These results suggested that fibrillated PTFE in the blend sample were stretched accompanied with elongational deformation of the samples. DSC measurements showed that amorphous phase existed in PTFE fibrils around $60 \%$, suggesting that the deformation of PTFE fibrils should occur in amorphous phase of the PTFE fibrils. We have concluded that the enhancement of the strainhardening property in the present system should be attributed to the generation of the restoring force by stretching PTFE fibrils.

\section{Acknowledgments}

We would like to acknowledge Dr. H. Aotani, Mr. S. Namura, Mr. A. Abe, and Dr. JC. Lee of DuPont-Mitsui Fluorochemicals Co., Ltd. for their helpful supports and valuable discussions.

\section{REFERENCES}

1) Li L, Masuda T, Takahashi M, Ohno H, Nihon Reoroji Gakkaishi, 16, 117 (1988). 
2) Koyama K, Nihon Reoroji Gakkaishi, 19, 174 (1991).

3) Meissner J, Hostettler, Rheol Acta, 33, 1 (1994).

4) Shinohara M, Nihon Reoroji Gakkaishi, 19, 118 (1991).

5) Ogura K, Takahashi M, Nihon Reoroji Gakkaishi, 28, 99 (2000).

6) Takahashi T, Takimoto J, Koyama K, J Appl Polym Sci, 72, 961 (1999).

7) Minegishi A, Nishioka A, Takahashi T, Masubuchi Y, Takimoto J, Koyama K, Rheol Acta, 40, 329 (2001).

8) Sugimoto M, Masubuchi Y, Takimoto J, Koyama K, Macromolecules, 34 (17), 6056 (2001).

9) Kurzbeck S, Oster F, Munstedt H, J Rheol, 43 (2), 359 (1999).

10) Takahashi $\mathrm{T}, \mathrm{Wu} \mathrm{W}$, Toda H, Takimoto J, Akatuka T, Koyama K, J Non-Newtonian Fluid Mech, 68, 259 (1997).

11) Takahashi T, Takimoto J, Koyama K, Polym Compos, 20 (3), 357 (1999).

12) Kurose T, Takahashi T, Koyama K, Nihon Reoroji Gakkaishi, 31, 195 (2003).

13) Yamamoto T, Hara T, Polymer, 23, 521 (1982).

14) Yamanoue T, Sawai D, Nakamura K, Morooka N, Kanamoto T, Nihon Reoroji Gakkaishi, 30, 295 (2002).
15) Doi M, Edwards SF, "The theory of polymer dynamics", (1986), Clarendon, Oxford.

16) Kitano T, Kataoka T, Nagatsuka Y, Rheol Acta, 23, 20 (1984).

17) Aoki Y, Hatano A, Watabe H, Macromolecules, 34, 3100 (2001).

18) Aoki Y, Hatano A, Watanabe H, Nihon Reoroji Gakkaishi, 30, 59 (2002).

19) Osaki K, Rheol Acta, 32, 429 (1993).

20) Guth E, Gold O, Phys Rev, 53, 322 (1938).

21) Rahl FJ, Evanco MA, Fredericks RJ, J Polym Sci A-2 Poly Phys, 10, 1337 (1972).

22) Chanzy HD, Smith P, J Polym Sci Polym Lett Ed, 24, 557 (1986).

23) Endo R, Jounai K, Uehara H, Kanamoto T, Porter RS, J Polym Sci Part B Polym Phys, 36, 2551 (1998).

24) Satokawa T, “Fluoro resin handbook”, (1990), Nikkan Kogyo Shinbun, Tokyo.

25) Starkweather HW, J Polym Sci Polym Phys Ed, 20, 2159 (1982). 